\title{
Salivary diagnostic of COVID-19: sailing between Scylla and Charybdis
}

\section{ROBINSON SABINO-SILVA ${ }^{1}$}

\author{
${ }^{1}$ Affiliation not available
}

August 7, 2020

\begin{abstract}
Coronavirus disease 2019 (COVID-19) is a global health problem which is challenging healthcare worldwide. In this critical review, we discussed the advantages and limitations of the rapid implementation of salivary diagnostic platforms to COVID19. The diagnostic test of COVID-19 by invasive nasopharyngeal collection is uncomfortable to the patients and requires specialized training to healthcare professionals in order to perform an appropriate collection of samples. Additionally, these professionals are in close contact with infected patients or suspected cases of COVID-19, leading to increased contamination risk for frontline healthcare workers (Scylla). Although there is a colossal demand for novel diagnostic platforms with non-invasive and self-collection samples to COVID-19, the implementation of the salivary platforms remains in debate due to its accuracy (Charybdis). Up to date, clinical trials supports the potential of detecting SARS-CoV-2 RNA in saliva as a biomarker for COVID-19, providing a self-collection, non-invasive, safety, and comfortable procedure. Therefore, the salivary diagnosis is suitable to protect healthcare professionals and others frontline workers, and may encourage patients to be tested due to its advantages over the current invasive methods. Furthermore, we expected that salivary diagnostic devices to COVID-19 continue to be used with austerity without excluding traditional gold standard specimens to detect SARS-CoV-2.
\end{abstract}

\section{Hosted file}

Caixeta et al. critical review Authorea.pdf available at https://authorea.com/users/349534/ articles/474532-salivary-diagnostic-of-covid-19-sailing-between-scylla-and-charybdis 